\title{
A Techno-Economic Analysis of Australian Green Steel Production from Hydrogen
}

Changlong Wang ${ }^{\mathrm{a}}$,*, Stuart D.C. Walsh ${ }^{\mathrm{a}}$, Zhehan Weng ${ }^{\mathrm{b}}$, Andrew Feitz ${ }^{\mathrm{b}}$, Marcus W. Haynes ${ }^{\mathrm{b}}$

${ }^{a}$ Civil Engineering, Monash University, Australia

${ }^{\mathrm{b}}$ Geoscience Australia, Canberra, Australia

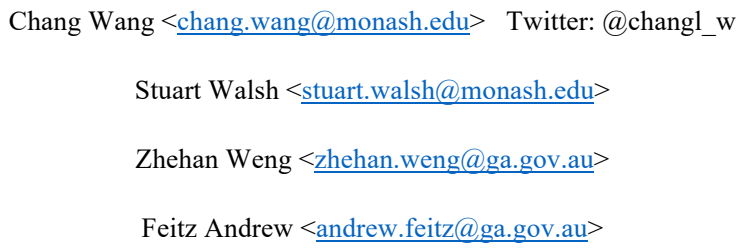




\title{
A Techno-Economic Analysis of Australian Green Steel Production from Hydrogen
}

\author{
Changlong Wanga,*, Stuart D.C. Walsh ${ }^{\mathrm{a}}$, Zhehan Weng ${ }^{\mathrm{b}}$, Andrew Feitz ${ }^{\mathrm{b}}$, \\ Marcus W. Haynes ${ }^{b}$ \\ ${ }^{a}$ Civil Engineering, Monash University, Australia \\ ${ }^{b}$ Geoscience Australia, Canberra, Australia
}

\begin{abstract}
Green steel - produced using hydrogen and electricity from renewable energy sources - provides both the means to decarbonize steel manufacturing, and a way to facilitate growth of the international hydrogen industry. Australia, with its abundant renewable resources and ample iron-ore deposits, is in an excellent position to participate in this opportunity. We highlight the synergies between the Australian iron-ore industry and the production of green-hydrogen from renewable energy sources. We identify high-potential areas for green steel production by cross-referencing regions of current and future iron-ore extraction against areas of high economic potential for hydrogen production. From these, we select two regions, the Pilbara region of North-Western Australia and the Eyre Peninsula in South Australia, for more detailed case studies.

The analysis highlights the advantages of well-optimised generation mix (in terms of wind, solar, battery, grid-connection and salt cavern storage, etc.) in decreasing storage requirements and the resulting production costs. We also demonstrate that green steel production costs could be reduced further if the system could use grid electricity to balance onsite renewable power by participating in the electricity spot market and operating flexibly.
\end{abstract}

Keywords: Green steel, Green hydrogen, Resource economics

${ }^{*}$ Corresponding Author

Email address: chang.wang@monash.edu (Changlong Wang) 


\section{Introduction}

As a net-energy exporter with ample renewable energy resources and deep expertise in international trade, Australia seeks to leverage its competitive advantages to become a major player in the emerging hydrogen industry [6]. However, there are costs and technical challenges in direct hydrogen export to overcome before this potential can be realized. A potential opportunity to help to start this industry may be through the export of embodied hydrogen, employed in the production of secondary products. In particular, hydrogen can be used to replace coking coal in steel production. Green steel (i.e. steel produced using hydrogen from renewable sources as the reducing agent) shows particular promise for the trade of embodied hydrogen from Australia [19, 7]. Australia is the world's largest producer of iron ore, exporting over $835 \mathrm{Mt}$ - around 36\% of global production - in 2019 [13]. Many centres of iron ore production are also host to excellent renewable wind and solar resources [10, 17]. Importantly, the presence of mining operations in these areas increases the economic potential for renewable projects by supplying the necessary infrastructure for energy generation, such as powerlines and transportation networks.

Implemented successfully, production of green steel has the ability to add value to Australian trade, reduce global greenhouse emissions, and futureproof Australian exports against international carbon-based tariffs. The purpose of this paper is to outline the potential opportunities for green steel production and export in Australia, and highlight the competitive advantage offered by Australia's renewable resources.

Production of green steel involves different processing pathways to conventional steel-making methods. The reduction of iron ore via smelting in a conventional blast furnace is replaced by a two-step process in which the ore is first reduced in a hydrogen-based shaft furnace, after which the reduced iron is then cast in an electric-arc furnace. For green steel, the energy for both processes is provided from renewable sources: as green hydrogen in the shaft-furnace reduction and as electricity for the electric-arc casting. Successful green-steel projects requires the combination of quality renewable energy resources with abundant iron-ore deposits.

This paper assesses the factors contributing to Australia's potential for green steel production and identifies key regions of interest for this nascent industry. Using data from Geoscience Australia's OZMIN database [4], we highlight regions of current and future iron ore production suitable for the 
production of green steel (Section 2). These regions are cross-referenced against areas of high potential for hydrogen production identified by Geoscience Australia's Hydrogen Economic Fairways Tool (HEFT) [17, 11].

After initial screening, we select two high potential locations for further temporal analysis with hourly wind and solar data: the Pilbara region of North-Western Australia; and the Eyre Peninsula in South Australia. These two regions have been selected as they present illustrative examples of green steel production potential from both off-grid and on-grid energy sources. Both locations possess significant renewable resources and abundant iron ore reserves, and have recently been listed as prospective hydrogen hubs [9] by the Federal Government. Furthermore, both locations have their own unique geological advantages: the Pilbara has access to large-scale low-cost salt cavern storage; whereas the Eyre Peninsula has access to the National Electricity Market with increasing renewables curtailment.

Using a detailed Mixed Integer Linear Programming (MILP) model designed to find the optimal mix of renewable energy sources for green steel production, we present results estimating the levelized cost of green steel production in both regions (Section 3). The results of the analysis quantify the benefit of these unique features and highlight the advantages of a well-optimised wind and solar generation mix in the region - decreasing production costs by reducing the need for additional energy storage and grid electricity for renewable "firm-up" and "balance of plant" purposes.

\section{Regions of high potential for green steel production}

In this section, existing databases describing i) the extent of Australia's current iron ore deposits and production pathways [4], are cross-referenced with ii) an assessment of the regions of high potential for future hydrogen production [17].

Australia hosts significant iron ore deposits in all of its states and territories, with the exception of the Australian Capital Territory [4]. The vast majority of Australian iron-ore production comes from the state of Western Australia, which contains approximately 92 percent of Australia's economic demonstrated resources [13]. The bulk of Western Australian iron ore is produced from a region in the North-West, known as the Pilbara. The Australian state with the second-highest concentration of iron ore deposits is South Australia. A significant number of these deposits are located in the Eyre Peninsula on the southern coast, bordered by the Great Australian 
bight. The locations of significant iron ore deposits are shown as circles on Figure 1. Expanded views of the Pilbara and Eyre Penisula are given in Figure $1 \mathrm{~b}$ and Figure $1 \mathrm{k}$ respectively.

Figure 1 also shows the distribution of regions across Australia that are economically favourable for Green Hydrogen production. These "Economic Fairways" have been identified using the HEFT recently developed by Geoscience Australia and Monash University [16, 17]. The HEFT analysis accounts for both the quality of the renewable energy source, the availability of local infrastructure (road, rail, water and power) as well as plant economics when assessing the potential for hydrogen production. Here, we assume that the hydrogen produced is consumed locally, and that the plant is connected to both the closest road (for construction and site access) and the nearest transmission line (as a source of backup power). We consider three different sources of renewable energy - solar only, wind only and a hybrid system with $50 \%$ wind and solar power.

The results of our analysis given in Figure 1 show a striking alignment between the distribution of high potential regions for hydrogen production and existing centres of mining activity. At first it may appear counter intuitive that surface renewable resources (solar and wind) are associated with regions of mineral extraction. However, this correspondence stems not from geology, but available infrastructure. Australia is blessed with ample areas of high-quality renewable resources. However, it is also vast and sparsely populated, and many regions lack easy access to power and roads. Large mining operations, such as iron ore, provide an economic incentive to develop electricity transmission and transportation infrastructure (roads and rail lines). Hence in Australia, the most economically favoured sites for renewable energy production (solar power in particular) often lie close to centres of mining activity.

\section{Green steel production model}

Here, we employ a site-based model to conduct a more detailed evaluation of the economics of green-steel production in particular regions. In Section 4 this model will be used to assess off-grid green steel production in the Pilbara region, and on-grid production at the Eyre Peninsular.

To assess the potential for green steel production at specific sites, we have developed a Mixed Integer Programming (MIP) model: 'Melbourne/Monash 


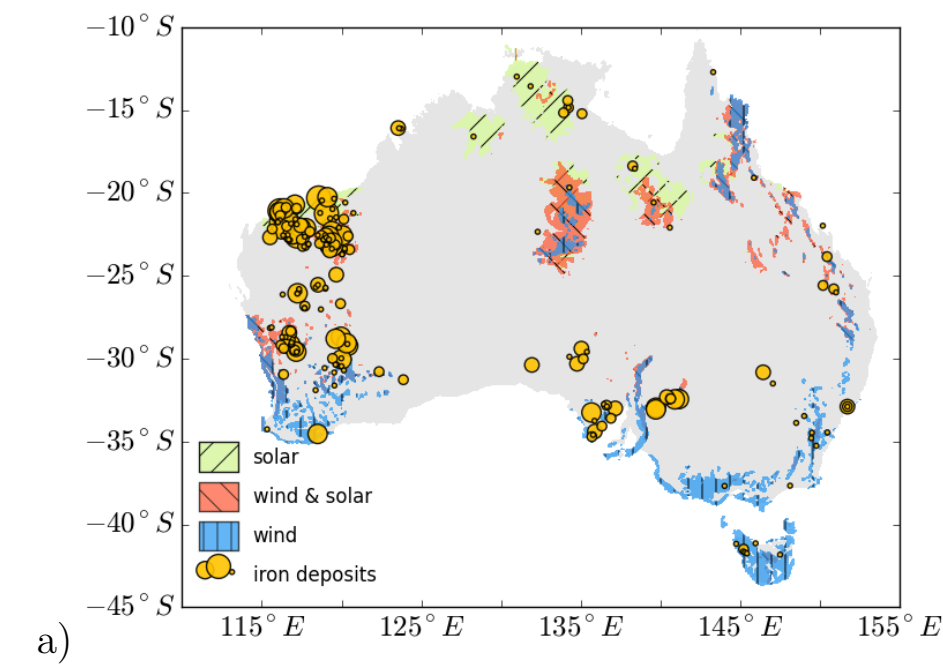

a)

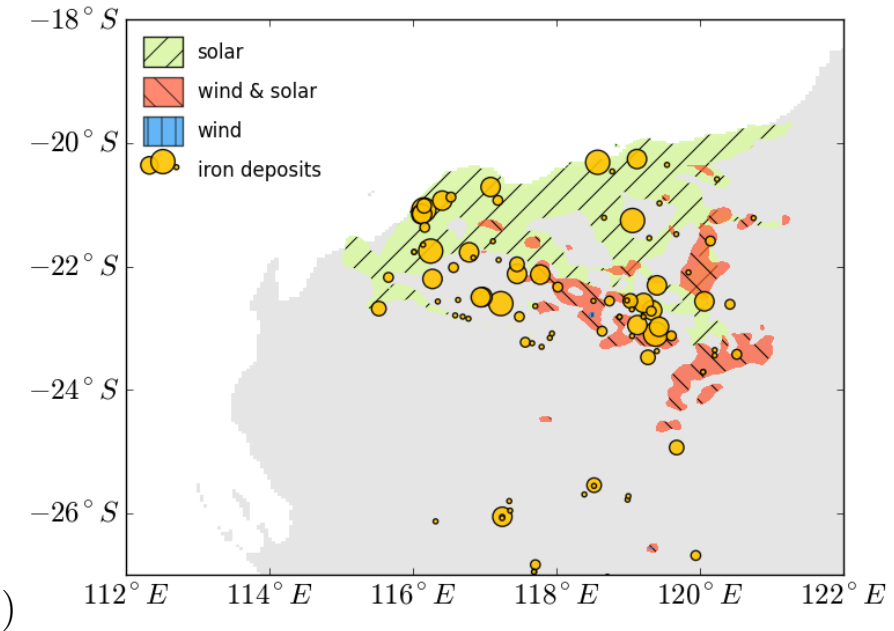

b)

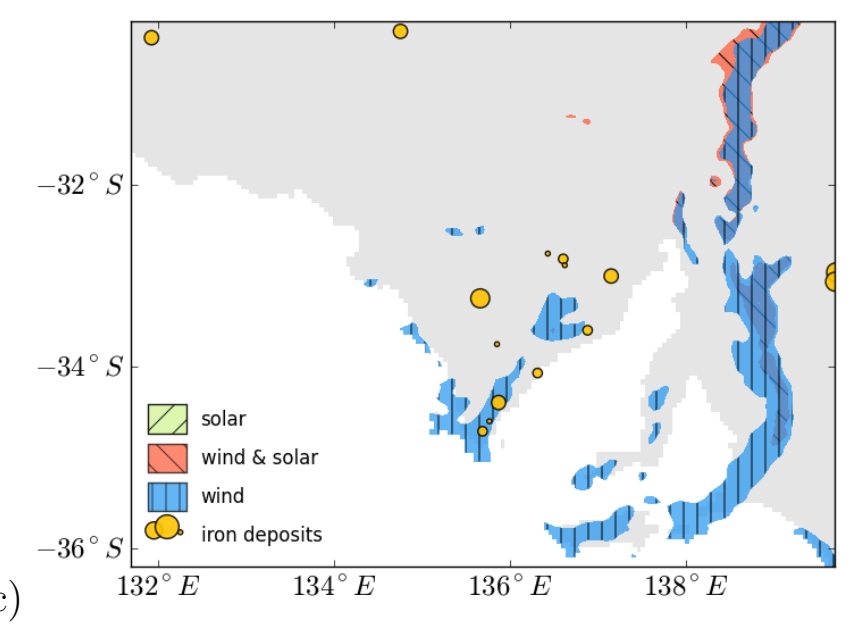

Figure 1: High potential regions for the preduction of farm-gate and off-grid hydrogen from solar, wind and hybrid (wind \& solar) Sources, and locations of iron ore deposits in Australia (upper) and the Pilbara region of Western Australia (lower). The size of the symbol reflects deposit size category. 
University Renewable Energy Integration Lab“ (MUREIL)-Steel.” MUREILSteel is based on an earlier model, MUREIL-Ammonia, designed to assess the production potential of green ammonia [18]. Like MUREIL-Ammonia, MUREIL-Steel is able to evaluate the impact of the temporal operational flexibility of electrolysers and the refining process on the optimal design of the a green-steel production system based on hourly wind and solar data. Figure 2 presents a schematic outline of the major components in the MUREIL-Steel model.

The model assumes that electricity for powering Polymer Electrolyte Membrane(PEM) electrolysers, the Hydrogen Direct Reduction (HDR) furnace and the Electric Arc Furnace (EAF) for steel manufacturing can be supplied by onsite wind, solar photo-voltaic or a hybrid system. This system may be supported by a 2, 4 or 6-hour Battery Energy Storage System (BESS) as well as a hydrogen buffer tank and geological storage. Cost-optimal designs are calculated among these generation and storage options to produce green steel at a daily output of 1000 tonnes. The model also considers the possibility that electricity can also come from the grid directly for balancing wind and solar PV in South Australia.

Input assumptions are critical to techo-economic modelling. The average annual wind and solar capacity factors in 2019, which indicate renewable resources quality for the two selected locations are retrieved from the Renewables.ninja model described by [12, 14]. The discount rate is assumed to be 10 per cent. Most of the facilities are assumed to have an economic life of 25 years, whereas PEM stacks lifetime is assumed to be 80,000 hours of operation. Other key technology capital expenses are taken from the AEMO ISP 2022 [1] Inputs and Assumptions Workbook and BloombergNEF [5], as summarised in Table 1. A Specific Energy Consumption (SEC) of 4.48 $\mathrm{MWh} / \mathrm{t}$ of liquid steel was calculated for all generation scenarios. For 24/7 operation on $100 \%$ Hot Briquetted Iron (HBI), the production of one tonne of liquid steel requires approximately $1500 \mathrm{~kg}$ of iron ore pellets. Here, it is assumed that $72 \mathrm{~kg}$ of hydrogen is needed per tonne of liquid steel [19].

According to [15], the electrolyser consumes two thirds of the energy, with the electric arc furnace (EAF) and the ore heating processes as further large energy users. Energy consumption of the shaft is minimal, due to the use of recovered heat from the condenser, as illustrated in Figure 2.

The above values only consider iron- and steelmaking without the further energy demand in the pelletizing process as well as in secondary metallurgy, casting and rolling. Pelletizing is required for magnetite processing, but not 
Table 1: Key cost assumptions employed in the MUREIL-Steel Model.

\begin{tabular}{ll}
\hline Component & Cost (AUD) \\
\hline PEM electrolysers & $\$ 1796 / \mathrm{kW}$ \\
Wind & $\$ 1991 / \mathrm{kW}$ \\
Solar PV & $\$ 1058 / \mathrm{kW}$ \\
Battery Energy Storage System $(2 \mathrm{~h})$ & $\$ 902 / \mathrm{kW}$ \\
Battery Energy Storage System $(4 \mathrm{~h})$ & $\$ 1377 / \mathrm{kW}$ \\
Battery Energy Storage System $(6 \mathrm{~h})$ & $\$ 1800 / \mathrm{kW}$ \\
& \\
H2 tank (with compressor) & $\$ 20 / \mathrm{kWh}$ \\
H2 geological storage (with compressor) & $\$ 4 / \mathrm{kWh}$ \\
Electric Arc Furnace & $\$ 300 /$ ton crude steel per annum \\
Hydrogen Direct Reduction shaft & $\$ 370 /$ ton crude steel per annum \\
Transmission grid charges & $\$ 20 / \mathrm{MWh}$ \\
Iron ore (pellets) & $\$ 140 /$ ton crude steel (adjusted) \\
Non-fuel OPEX & $\$ 100 /$ ton crude steel \\
Grid electricity in SA & Based on hourly spot market prices in \\
& 2019 for renewables firm-up \\
\hline
\end{tabular}

${ }^{*}$ Cost based on nameplate capacity, i.e. annual capacity at $100 \%$ operation.

processing of haematite ores. Pelletizing and rolling in particular require additional inputs in the form of both fuel and electricity [20, 15].

Flexible Electric Arc Furnace operation is currently practical and in use to process scrap metal feedstock within Australia [e.g. 3]. With grid connection, EAFs can be rapidly started and stopped, allowing the steel mill to vary energy consumption according to electricity prices or onsite variations in renewable energy generation.

If the electrolyser is sized larger than required for operation at 100 per cent capacity factor, flexibility can be added into the system to cope with renewable variability and to take advantage of price fluctuations in the spot market. Hydrogen from storage then opens up the possibility to offer positive reserve power by reducing the electrolyser load when electricity prices are high.

With these operation constraints, optimal sizing of the onsite wind, solar PV, electricity storage, hydrogen buffer and the HDR-ERF system are simultaneously determined by the MIP model to meet a production goal of 1000 tonnes of liquid steel per day. The levelised costs of liquid steel is then derived based on the production volume, the plant costs (of the optimised 


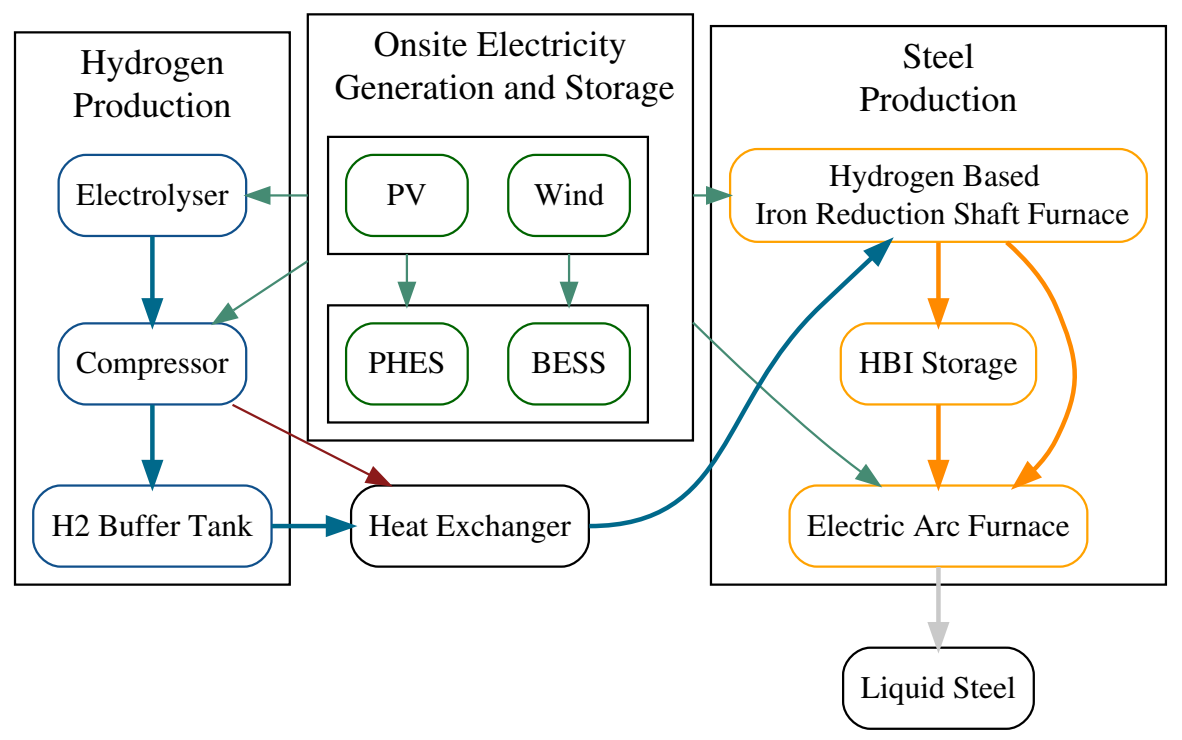

Figure 2: Schematic outlining the major components considered by the MUREIL-Steel model.

system components), their operational expenditures, and the iron ore costs, etc.

\section{Discussion of production-model results}

Here we use the production model to assess the green steel production in two different locations using different power sources. We compare the results from (i) wind only, (ii) solar photovoltaics (solar PV) only and (iii) hybrid wind-solar systems for the Pilbara in Western Australia. We also consider what effect participating in the electricity grid may have on the economics of production by considering a fourth case study (iv) hybrid wind-solar systems with grid access at the Eyre Peninsula in South Australia. South Australia is a particularly attractive electricity market due to a high penetration of renewable resources and extended periods of low (and often negative) electricity prices. Results from the MUREIL-Steel analysis are presented in Figure 3. The figure shows the relative contribution of individual components to the overall least-cost of steel production in the selected regions.

For steel production in the Pilbara region, wind alone powered system is very expensive due to significant overcapacity and curtailment. Because of 


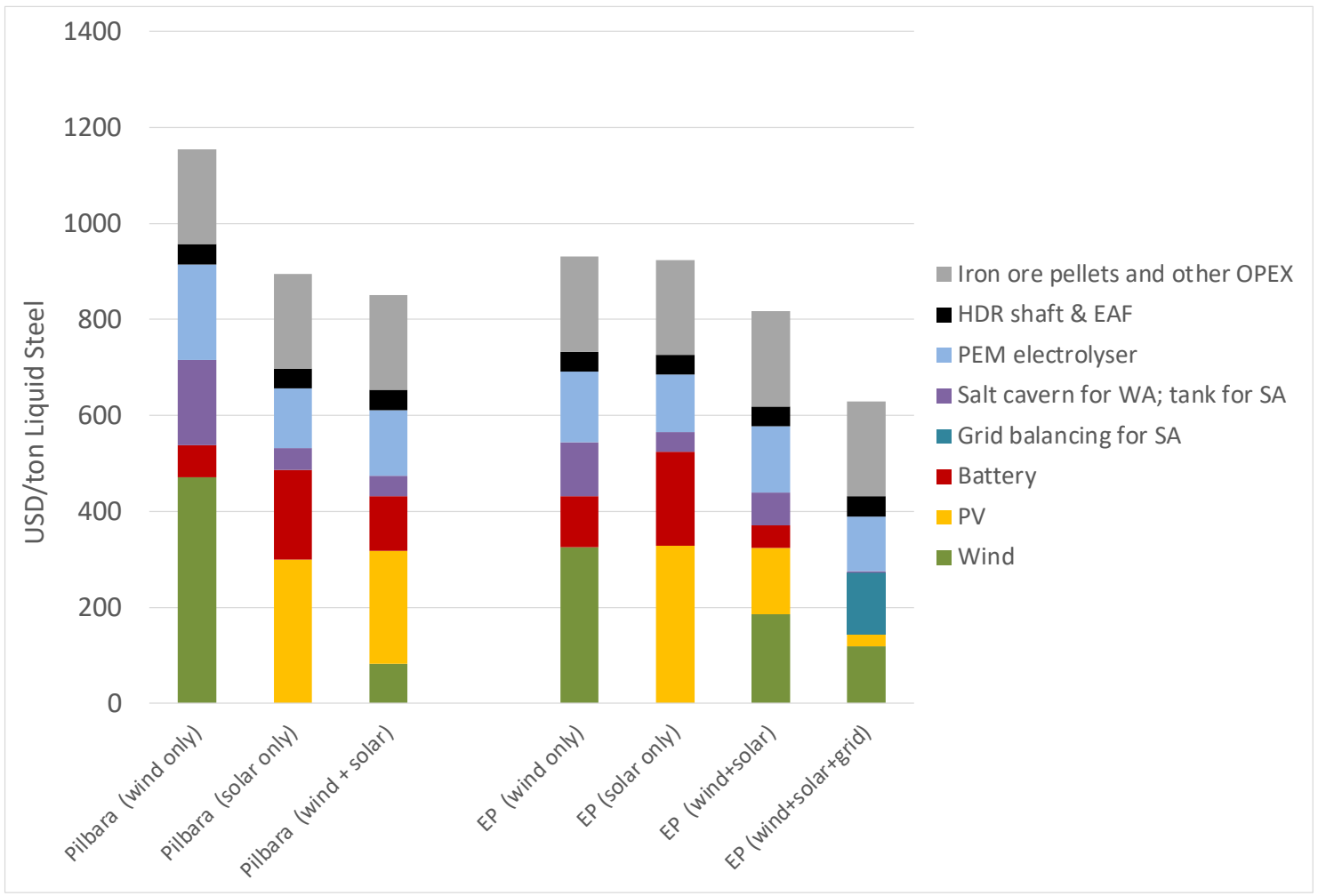

Figure 3: Levelised costs of steel production in the Pilbara (Western Australia), and the Eyre Peninsula (South Australia) with 100\% Direct Reduced Iron (i.e. no recycled steel).

the high seasonality of the wind resources in the Pilbara region, it would require significant seasonal salt cavern storage to meet the temporal production target.

While solar PV powered system is about $20 \%$ cheaper than wind in the Pilbara, a significantly larger amount of battery storage is required to enable the system to operate during the night.

The model further indicates the advantages of a well-optimised generation mix of wind and solar to increase plant capacity factor and to reduce the overall production costs for both the Pilbara and the Eyre Peninsula. Due to the plant's ability to respond to energy supply by balancing demand from both smelting and hydrogen generation, a relatively small amount of additional battery storage and hydrogen storage is required for mixed wind and solar projects.

In addition to production from off-grid renewable resources, an optimised 
electricity system can facilitate green steel production. Our analysis in South Australia suggests that green steel production may be more competitive, if it can participate in the spot market by operating flexibly. However, it should be noted that this analysis assumes that the additional demand provided by the plant does not alter the electricity price (i.e., the plant acts as a price taker only).

\section{Conclusions}

Flexible green steel production enabled by the Hydrogen Direct Reduction/Electric Arc Furnace system presents significant economic opportunities for Australia. Many current iron-ore mining centres are also particularly suited for hydrogen production from renewable resources, due to enabling power and transportation infrastructure built to service existing mining operations.

Here, we have presented case studies considering a more detailed analysis of green steel production in two of these areas: the Pilbara region in northwestern Australia; and the Eyre peninsular in South Australia. Our analysis considers how the practical application of the HDR-EAF system will be influenced by the volatility of energy prices, the design of the spot markets, as well as the steel and scrap markets and other technical concerns. The modelling results indicate that a whole-of-system planning approach that co-optimises power system capacity expansion with green steel production would benefit both sectors.

Future study will estimate to what extent electricity consumption for flexible steel manufacturing will effect the spot market. The "price-taker" assumption in this study is based on the expectation that increasing wind and solar electricity production will be deployed onto the grid [1]. In addition, it should be noted that there might be other revenue streams for flexible steel manufacturing, such as providing Frequency Control Ancillary Services [8], participating in the wholesale demand response market [2], etc. These considerations will be further scrutinised in later studies.

\section{Acknowledgements}

We acknowledge the traditional custodians of country throughout Australia and recognises their continuing connection to lands, waters and communities. We pay our respects to Aboriginal and Torres Strait Islanders' cultures and to elders past, present and emerging. 
This work is a product of a collaborative project between Geoscience Australia and Monash University as part of the Exploring for the Future program. Zhehan Weng, Andrew Feitz and Marcus Haynes publish with the permission of the CEO of Geoscience Australia.

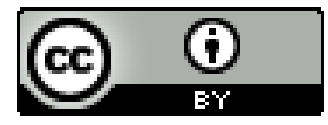

(C) Monash University \& Commonwealth of Australia (Geoscience Australia) 2021.

This product is released under the Creative Commons Attribution 4.0 International Licence (http://creativecommons.org/licenses/by/4.0/legalcode).

\section{References}

[1] AEMO, 2021. Integrated system plan for the national electricity market. URL: https://aemo.com.au/en/energy-systems/ major-publications/integrated-system-plan-isp/ 2022-integrated-system-plan-isp.

[2] AEMO, 2021. Wholesale demand response mechanism. URL: https://aemo.com.au/en/initiatives/trials-and-initiatives/ wholesale-demand-response-mechanism.

[3] ASI, 2021. Capabilities of the Australian steel industry to supply major projects in Australia. Technical Report.

[4] Australia, G., 2021. OZMIN Mineral Deposits Database.

[5] Bloomberg New Energy Finance, 2020. Hydrogen - the economics of production from renewables, full report. Technical Report. Bloomberg.

[6] COAG Energy Council Hydrogen Working Group, 2019. Australia's national hydrogen strategy .

[7] DISER, 2020. Technology Investment Roadmap: First Low Emissions Technology Statement. Technical Report.

[8] Dozein, M.G., Jalali, A., Mancarella, P., 2021. Fast frequency response from utility-scale hydrogen electrolyzers. IEEE Transactions on Sustainable Energy 12, 1707-1717. doi:10.1109/TSTE.2021.3063245. 
[9] Federal Department of Industry Science, Energy and Resources, . Future hydrogen industry to create jobs, lower emissions and boost regional Australia - The Hon Angus Taylor MP Media Releases. URL: https://www. minister.industry.gov.au/ministers/taylor/media-releases/ future-hydrogen-industry-create-jobs-lower-emissions-and-boost-regional-austr

[10] Feitz, A.J., Coghlan, R., Tenthorey, E., 2019. Prospective Hydrogen Production Regions of Australia. Technical Report. Geoscience Australia.

[11] Geoscience Australia, 2021. The Hydrogen Economic Fairways Tool (HEFT). URL: https://portal.ga.gov.au/persona/heft.

[12] Pfenninger, S., Staffell, I., 2016. Long-term patterns of European PV output using 30 years of validated hourly reanalysis and satellite data. Energy 114, 1251-1265.

[13] Senior, A., Britt, A., Summerfield, D., Hughes, A., Hitchman, A., Cross, A., Champion, D., Huston, D., Bastrakov, E., Sexton, M., Moloney, J., Pheeney, J., M., T., Schofield, A., 2020. Australia's identified mineral resources doi:10.11636/1327-1466.2020.

[14] Staffell, I., Pfenninger, S., 2016. Using bias-corrected reanalysis to simulate current and future wind power output. Energy 114, 1224-1239.

[15] Vogl, V., Åhman, M., Nilsson, L.J., 2018. Assessment of hydrogen direct reduction for fossil-free steelmaking. Journal of Cleaner Production 203, 736-745. doi:10.1016/j.jclepro.2018.08.279.

[16] Walsh, S.D., Northey, S.A., Huston, D., Yellishetty, M., Czarnota, K., 2020. Bluecap: A geospatial model to assess regional economic-viability for mineral resource development. Resources Policy 66, 101598.

[17] Walsh, S.D.C., Easton, L., Weng, Z., Wang, C., Moloney, J., Feitz, A., 2021. Evaluating the economic fairways for hydrogen production in australia, in press.

[18] Wang, C., Walsh, S., Dargaville, R., 2021. Evaluating the Economic Potential for Green Ammonia Production in Australia, International Conference on Applied Energy 2021. pp. 1-6. 
[19] Wood, T., Dundas, G., Ha, J., 2020. Start with Steel: a practical plan to support carbon workers and cut emissions. Grattan Institute.

[20] Worrell, E., Price, L., Neelis, M., Galitsky, C., Zhou, N., 2008. World best practice energy intensity values for selected industrial sectors . 